\title{
O Brasil das luzes francesas
}

\author{
FRANÇOIS MOUREAU
}

$\mathrm{N}$

O Pensamento DA França das luzes, o Brasil é, de algum modo, uma zona de sombra; sua presença, porém, por mais fugitiva que seja, não deixa de ser responsável por certas ambigüidades da reflexão filosófica, científica e política da Europa ilustrada. Pois, foi a América espanhola que concentrou o interesse dos intelectuais franceses durante as décadas que antecederam a Revolução francesa. Se, com seus projetos aventurosos de França equinocial e França antártica, com esse seu fascínio pelo pau-brasil e os costumes tupinambás, estimulado pelos textos de Thevet, Léry e as gravuras de De Bry, o século XVI faz do Brasil uma terra onde o mundo às avessas cumpre plenamente seu papel de objeto-espelho (1), o século seguinte (2) volta seu olhar americano mais para o Norte, para a Guiana, a Flórida, até mesmo a Nouvelle France (o Canadá).

A América do Sul parece entregue aos conquistadores espanhóis. Depois de 1640, quando Portugal renasce, a marinha mercante francesa já se dirige para outros locais de comércio: a rota das especiarias e suas feitorias através do Atlântico sul e do oceano Índico, o Atlântico norte em direção ao Canadá, e o mar do Caribe no que diz respeito às Antilhas de onde a França tira o açúcar que ela não pede ao Brasil. Durante a guerra da Sucessão da Espanha, na qual Portugal colocou-se do lado dos inimigos da França, é que o Brasil, nova e fugazmente iria encontrar um lugar no imaginário francês. Aquela baía do Rio de Janeiro que fora o berço do sonho brasileiro de Villegagnon no século XVI (3) torna-se em 1711 o lugar em que se enfrentam duas potências coloniais bastante indiferentes à paisagem que é $\mathrm{o}$ cenário das peripécias do conflito. Duguay-Trouin e sua esquadra de navios corsários, armada por particulares de Saint-Malo, bombardeiam a cidade do Rio de Janeiro e levam, como o escreve o próprio chefe da expedição em suas memórias, "o nome francês a um novo mundo" (4). A descrição, fornecida por ele, do Rio de Janeiro é puramente militar e ele se mantém isento de qualquer sensibilidade ao espírito do lugar (5).

É provavelmente com Charles-Marie de la Condamine, cientista e, em certas circunstâncias, poeta, que o Brasil reaparece na geografia mítica dos franceses, um Brasil do rio e da floresta, o da Amazônia que o erudito acadêmico atravessa, partindo da costa do Pacífico e do Peru até a Guiana, um Brasil onde La Condamine busca em vão as amazonas (6), mas no qual descobre: 
"Um novo mundo, afastado de qualquer comércio humano, sobre um mar de água doce, no meio de um labirinto de lagos, rios e canais que penetram em todas as direções uma floresta que só por eles se torna acessível. Eu encontrava novas plantas, novos animais, novos homens (7).”

Antes mesmo da publicação dos relatos de viagem de La Condamine, um compilador como o abade Claude-Marie Guyon dedica o último capítulo de sua Histoire des Amazones anciennes et modernes (Paris, 1740, 2 v.) à misteriosa ressurgência americana do romanesco mito antigo. Mas a viagem do rio das amazonas, a partir da costa do Pacífico, diz respeito fundamentalmente a cientistas, naturalistas ou astrônomos: é o caso do mínimo Louis Feuillée, matemático e botânico (8), de Jean Godin des Odonais, que, em 1749, desceu o rio Amazonas até o Pará, de onde foi para Caiena (9), do médico naturalista Jean Dombey entre 1778 e 1785 (10), do botânico Jean-Baptiste Fusée-Aublet (1723-1778) que foi um dos primeiros a desenhar a flora amazônica (11), do médico Pierre Barrière, do geógrafo Joseph Gumilla (12) ou de Louis Claude Richard, membro da Academia de Ciências, que percorreu em 1781 as ilhas da foz do rio Amazonas. Pouco se interessam essas viagens de descobrimento pelas populações, esquecidas em benefício da mineralogia, da fauna e da flora, fontes eventuais de lucros coloniais tanto quanto de comunicações acadêmicas (13).

Entretanto, no fim do século, Bernardin de Saint-Pierre, em Fragments de l'Amazone (14), faz desses lugares misteriosos o cenário de uma renovação utópica, da regeneração dos europeus: o autor de Paul et Virginie, que das regiões tropicais só conheceu a Ilha de França (atual ilha Maurício) onde se localiza sua obra-prima, imagina huguenotes franceses - eco consciente dos empreendimentos calvinistas no Brasil na época do Renascimento? em busca de um mundo virgem para ali construir a Nova Genebra e o país da realização utópica. Conduzida por Antoine Bénezet - duplo de um François Leguat que teve o mesmo projeto no oceano Índico - a diáspora huguenote expulsa da França em 1685 pela revocação do Édito de Nantes, estabelece na Amazônia a civilização da natureza reconciliada com a sociedade. A redação desse texto se situa em plena Revolução francesa, depois do Terror: tal sonho pacífico de uma América que seria o futuro da velha Europa corrupta e violenta é objeto de uma narrativa inacabada, como se o projeto se tivesse tornado improvável em demasia. No seu esboço de volta ao mundo, Candide ia de Portugal à América espanhola, e atravessava, entre uma bela pradaria entrecortada por riachos e bosques (cap. XVI), o espaço que separava Buenos Aires do Suriname passando pelas reduções do Paraguai e o Eldorado: o Brasil estava totalmente ausente desta visita sin- 
gular em pais desconhecido. Aliás, sabe-se o que Voltaire pensava sobre o Brasil e os brasileiros, um julgamento que deixa perceber muita coisa sobre o imaginário profundo de seu bestiário:

“... O brasileiro é um animal que ainda não atingiu o complemento de sua espécie, uma ave que só mui tardiamente cria as próprias penas, uma lagarta presa no seu casulo, que só daqui a alguns séculos tornar-se-á borboleta. Ele terá talvez um dia uns Newtons e Lockes, e então terá preenchido toda a extensão da carreira humana, desde que os órgãos do brasileiro sejam fortes e flexíveis bastante para chegar a esse termo: Pois tudo depende dos órgãos.” (15)

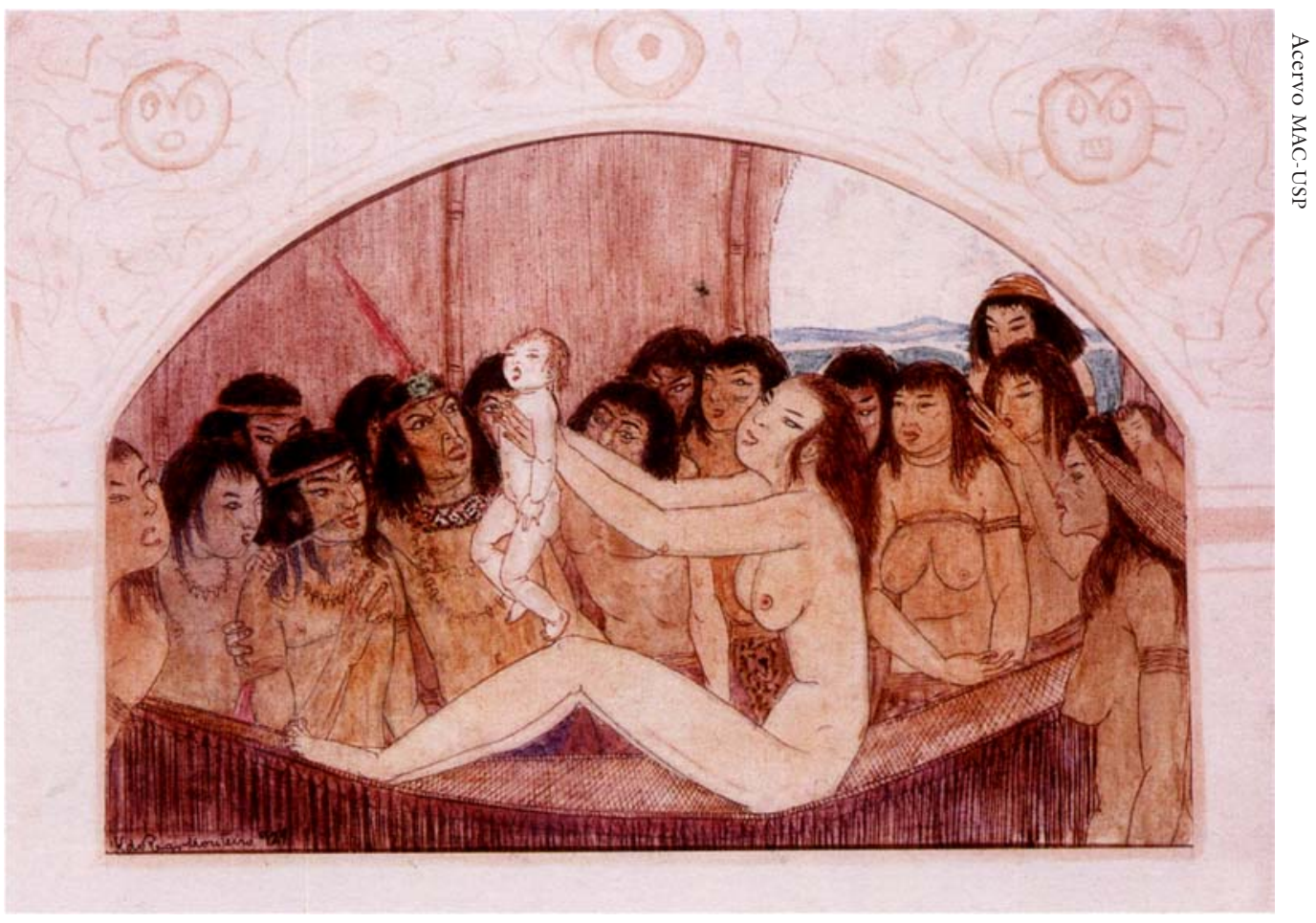

Vicente do Rego Monteiro (Recife, PE, 1899-1970).

Mani oca / O nascimento de Mani, 1921.

Aquarela e nanquim s/papel, $28 \times 36.5$, col. MAC-USP.

No mais das vezes, para os viajantes (16) franceses do século XVIII, o Brasil não passa de uma vasta extensão de terras maninhas destinadas a enriquecer tal ou qual nomenclatura de História natural: alguns ecos adicionais dos velhos fantasmas nascidos das narrativas do século XVI sobre os tupinambás repisam a lição canibal cujo significado equívoco é bastante problemático para nações européias que matam pelo simples prazer da guerra 
sem a necessidade de se alimentarem: "É melhor com certeza comer seus inimigos do que abandonar aos corvos e às gralhas o fruto se sua vitória" (17), Voltaire se regozija de que os Tupinamboux, que Pierre Boyle colocava entre os poucos povos naturalmente ateus, sejam simplesmente "verdadeiras crianças: uma criança nem atéia e nem deísta, ela não é nada"(18). Em De l'esprit des lois, Montesquieu só cita o Brasil por causa de suas riquezas em ouro (livro XXI, cap. 22).

A Histoire philosophique et politique des établissements et du commerce des Européens dans les deux Indes marca com toda a certeza o termo de uma certa forma de pensamento ilustrado sobre os empreendimentos coloniais e, particularmente, sobre as possessões portuguesas. A obra do abade Raynal, inicialmente publicada em 1770, antes de ser substancialmente aumentada por Diderot, é considerada o primeiro clássico francês do anticolonialismo. Graças a essa história dos grandes descobrimentos nos seus efeitos perversos sobre as civilizações chamadas primeiras, a reflexão política das últimas décadas do antigo regime anuncia uma etnologia do reconhecimento tanto quanto princípios que a Revolução francesa proclamou, mas nem sempre realizou. O Brasil está presente no tomo III da edição original por uma compilação de fontes diversas (19): A Histoire générale des voyages do abade Prévost, o que é bastante natural, mas também entre outras, Jean de Léry (20), Pierre du Jarric, Johannes de Laet, François Coréal ou La Condamine. As fontes portuguesas, entre as quais J. Osório da Fonseca, ele as conhece por traduções francesas ou por outras compilações. Mas a Histoire des deux Indes, que não cita a origem das informações, demonstra grande desconfiança em relação aos relatos de viagem. "Seja-me permitido dizer que não existe estado mais imoral que o de viajante" $(1780$, t. v, p.25), proclama Diderot (21) nessa edição da obra. Raynal prefere recorrer a informantes anônimos, talvez fictícios, como o foi "um dos homens mais ilustrados que jamais viveu no Brasil” (1780, t. v, 111) (22).

Já na primeira edição, Raynal, retomando a mesma cantilena já mencionada, descreve os brasileiros da idade do descobrimento como um povo de ateus felizes, e Diderot, por seu lado, lança alguma luz, ideologicamente orientada, sobre a ausência de "amor à pátria entre os selvagens" brasileiros, uma "hospitalidade [que] é um dos indícios mais significativos do instinto e destinação do homem para a sociabilidade", mas também sobre a contribuição positiva dos missionários jesuítas. O debate entre o código da natureza e a sociedade policiada, já aparece vigorosamente esboçado. A lista - aliás, incompleta - dos livros emprestados por Diderot à Biblioteca do Rei entre 1775 e 1782 não traz nada de novo sobre as fontes brasileiras (23). O estudo da terceira edição, chamada definitiva, de 1780 (24), que 
marca o termo da reflexão, por vezes, conflitante dos dois autores (25), conduz a uma síntese relativamente coerente - uma máquina de guerra, segundo a fórmula de M. Duchet (26) - que será o assunto de nossa comunicação. Em 1784, a parte brasileira de Histoire des deux Indes foi resumida e divulgada pela Encyclopédie méthodique de Panckoucke em sua seção Economie politique et diplomatique (27).

Será que a colonização portuguesa na Histoire des deux Indes é tratada de forma específica ou como um aspecto apenas da expansão imperialista de duas nações rivais da península ibérica (28)? Entre os 19 livros da edição de 1780, a Espanha (29) é o objeto principal de três deles - do sexto ao oitavo - que, basicamente, retomam a leyenda negra acompanhada por um comentário sem concessão. Numa apóstrofe célebre, Diderot, em nome da filosofia e da humanidade, dava uma lição aos reis da Espanha, e, em primeiro lugar, a Carlos III, o Bourbon ilustrado, convidando-os a "reparar o crime de [seus] predecessores e dos súditos destes" (livro VIII, t. VI, p. 453$)$.

Os ataques contra "esse povo pobre e soberbo", "reduzido à postura e estupidez do bruto", “aquele orgulho nacional, o mais cego que já existiu" (t. IV, p. 407; t. v, p. 71; t. III, p. 384) alcançam um grau de chauvinismo filosófico que é difícil não caracterizar como forma acabada de racismo cultural: “(...) e o espanhol mirrado, seminu, desleixadamente sentado no chão, olha com comiseração seus vizinhos que, bem alimentados, bem vestidos, trabalham e apenas riem de sua loucura" (IV, p. 406). Podemos imaginar a repercussão que tiveram na Espanha - mesmo nos meios ilustrados - essas caricaturas picarescas de nossos vizinhos do Sul: seguramente, havia ainda o aquém e o além-Pirineus. Mas, como freqüentemente acontece com Raynal, o discurso é mais ambíguo do que parece: sabe-se que houve em Versalhes, na origem da Histoire des deux Indes, relatórios, arquivos, até mesmo pedido da Administração das Colônias desejosa de tomar para o Rei o controle de territórios entregues à gestão da Compagnie des Indes (30).

Daí a crítica de um estatuto colonial privatizado que se julgava conveniente nacionalizar (31): o poder de Estado alimentado pelas idéias dos fisiocratas sobre o absurdo econômico que era a escravidão orientava-se para uma colonização moderna e produtiva da qual a prática ibérica não era certamente o modelo. Do lado da Espanha, o texto foi significativamente inspirado pelo embaixador em Paris, o muito ilustrado conde de Aranda, cujo secretário, Ignacio Heredia, revisou para a primeira edição tudo aquilo que dizia respeito às colônias da Coroa (32). 
No Portugal ilustrado de Pombal (33), o livro de Raynal não obteve melhor recepção, sendo proibido desde 1773 (34); um projeto de tradução também foi abandonado (35), enquanto em Madri uma adaptação em língua castelhana era publicada em 1784 pelo duque d'Almodóvar, cinco anos apenas depois da interdição do original francês pela Inquisição. Em março de 1781, um viajante francês que visita os livreiros de Lisboa verifica que as obras do "abade Raynal são rigorosamente proibidas pela Inquisição e todas as demais justiças do reino" (36). No entanto, encontra-se relativamente cedo no Brasil o indício da influência da obra (37): como o mostrou Kátia de Queirós Mattoso (38), a conspiração da Bahia em 1798 foi amplamente inspirada pelas luzes francesas, por Mably e Rousseau, como também por Raynal.

Mais ainda, já em 1789, na ocasião da devassa realizada sobre as atividades dos conspiradores de Vila Rica nas Minas Gerais, foi apreendido um exemplar dessa mesma obra na biblioteca do doutor José Pereira (39). Conforme os autos dos interrogatórios, um suspeito pretendeu a esse respeito "ter ouvido dizer (...) que havia nas mãos de certo doutor um livro de um autor francês (...) o qual, no fim, indicava - o modo de se fazerem os levantes - que era cortar a cabeça do governador e fazer um discurso para o povo" (40). Outro afirmou que "o abade Raynal era um escritor profético - um escritor de grandes vistas - porque havia previsto o levante da América do Norte" (41). Inútil precisar que nenhuma dessas declarações revolucionárias se achava explicitamente em Raynal, mas assim mesmo elas podiam ser inferidas de discursos um tanto exaltados, dos quais já citamos um exemplo e ao qual se pode juntar um apelo ao Espártaco negro que liberaria os escravos das colônias americanas (42).

Os 30 capítulos do livro primeiro da Histoire des deux Indes são integralmente dedicados ao Portugal dos Grandes Descobrimentos orientais; esse texto-frontispício testemunha da grave responsabilidade do reino num fenômeno novo da idade moderna: a colonização de territórios separados da metrópole por oceanos, até mesmo continentes inteiros. Ali Portugal impôs modelos imperialistas que as demais nações européias iriam em seguida copiar ou adaptar. Além disso, essas páginas demonstram o mecanismo histórico que conduz à grandeza e à decadência de um povo que reproduzia as fases do processo bem conhecido por que haviam passado as civilizações antigas. Raynal atribui os sucessos iniciais de Portugal a uma ligação entre uma aristocracia de origem francesa - ou borgonhesa - e a nobreza local, reforçada por uma forte coesão nacional em torno dos estados gerais (43): aí reconhecemos um eco das teorias germânicas do conde de Boulainvilliers sobre o governo feudal (44). 
A decadência de Portugal e sua absorção provisória pela Espanha de Felipe II são a conseqüência suicida de uma política econômica baseada na procura estéril do ouro e não na indristria nacional, e também de uma sociedade fechada, a qual foi logicamente substituída nas Índias pelo que Raynal denomina "uma nação livre, esclarecida e tolerante"(45): certamente já entendemos que ele está designando a Inglaterra. Neste livro primeiro, trata-se apenas da rota das Índias orientais. O Brasil está ausente. Como assinalamos supra, só no livro VI - terceiro tomo da edição de 1780 - é que aparecem as Índias ocidentais com um resumo da descoberta espanhola e da conquista do México. Ilustrado por dois mapas ( ${ }^{\text {os }} 34$ e 35 do atlas) traçados por Bonne, engenheiro hidrógrafo da marinha (46), o livro IX que forma a primeira parte do tomo $\mathrm{V}$ é por sua vez integralmente consagrado ao Estabelecimento dos portugueses no Brasil. Guerras que ali empreenderam. Produtos e riquezas desta Colônia. Mas o frontispício gravado por Moreau, o moço, e que abre o volume remete simbolicamente ao tomo I (47) e ao imperialismo português nas Índias orientais: a relação é assim indicada entre as duas faces de uma mesma política de conquista.

Além de um relato bastante esquematizado da luta dos colonizadores portugueses contra as outras nações predadoras do Brasil - os franceses frívolos e os hereges holandeses -, as paginas brasileiras oferecem uma imagem das populações ameríndias amplamente inspirada numa mitologia primitivista na qual Diderot já se exercitara no Supplément au voyage de Bongainville redigido e aumentado entre 1772 e 1780 depois de haver forjado o essencial já na edição de 1770 da Histoire des deux Indes: como outros taitianos, os antigos brasileiros não conheciam nem o meu nem o teu, viviam como ateus felizes numa anarquia que correspondia à sua total ignorância de qualquer potência sobrenatural, viam no amor à pátria um sentimento facticio (t. V, p. 19-20), praticavam com prudência a poligamia e hospitalidade para com os estrangeiros. Única diferença com os naturais da Polinésia, os brasileiros, como o haviam repetido à saciedade os viajantes quinhentistas, entregavam-se a um canibalismo que os homens das Luzes não sabiam como justificar (48), mesmo comparando-o com o assassinato legal que a guerra, para eles, representava (49). "A ambição reduzia-se a capturar prisioneiros que eram trucidados e comidos com aparato" (t. V, p. 28) (50), observa sobriamente a Histoire des deux Indes. Mas, ao contrário do que se poderia pensar, aquilo que, um pouco apressadamente, chamase de filosofia das Luzes era apenas parcialmente favorável a esses homens de uma natureza não aperfeiçoada. Um Cornelius de Pauw, que Diderot leu atentamente, considera, por exemplo, as populações indígenas o receptáculo privilegiado das epidemias e o túmulo dos colonos vindos da Europa $(51)$. 


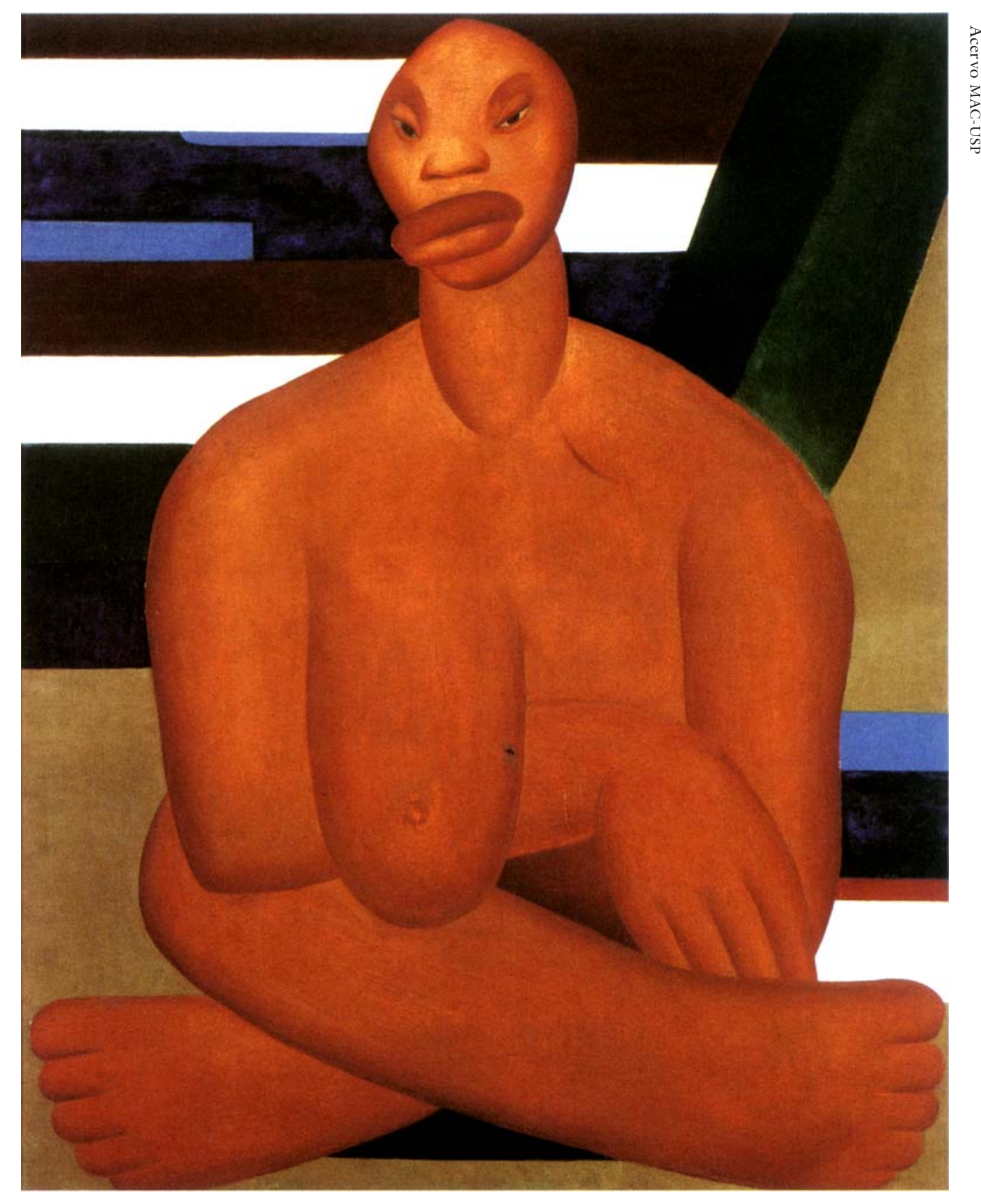

Tarsila do Amaral (Capivari, SP, 1886-1973).

A negra, 1923.

Óleo s/tela, $100 \times 81.3$

Doação MAMSP. 
O julgamento da Histoive des deux Indes sobre as populações nativas parece contrastar com o sentimento expresso por certa ideologia iluminista convicta da superioridade de seu discurso sobre o homem. Nem por isso deixa de estar na mesma linha dos intelectuais do Renascimento, de Las Casas, até Léry e Montaigne. Mas a solicitude do século das Luzes se dirige mais aos escravos negros do que aos índios, seus irmãos de infortúnio (52). A Histoire des deux Indes, por seu lado, vê o futuro do Brasil na mestiçagem das diversas raças que coabitavam no seu território, num melting pot cultural que reuniria todos os excluídos da Europa - judeus hereges, criminosos e "escória das sociedades policiadas" (53) - formando longe da metrópole uma nação nova que tomaria conta daquela terra sem nome que era o Brasil anterior à conquista e lhe legitimaria, de algum modo, a história sangrenta (t. V, p. 3 a 5).

No texto de Raynal não há tentação do retorno, apenas um sentimento de culpa consideravelmente reforçado pela reescritura de Diderot: "Entre homens cujas necessidades sejam recíprocas, o comércio se estabelece sem perturbação e logo eles se acostumam a olhar como amigos, como irmãos, aqueles que o interesse ou outros motivos conduzem à sua terra" (t. V, p. 4). Aquilo que Raynal denomina ação positiva dos "princípios especulativos" (t. V, p. 2) permite então passar do colonialismo coercitivo ao neocolonialismo da razão (54). Assim como em qualquer outra parte, fica excluído no Brasil o princípio das companhias monopolistas, sistema destruidor por excelência "num século de luz" (t. V, p. 95) (55). Desta forma o índio se torna o grande ausente de tal metamorfose do lugar colonial em nação emergente que o transforma em brasileiro - termo totalmente equívoco numa sociedade aberta à livre concorrência (56) dos homens e das mercadorias. Esse sentimento é compartilhado na mesma época pelo economista Accarias de Sérionne para quem a liberdade do comércio na Europa só pode favorecer Portugal e suas colônias, na medida que os efeitos inflacionistas da massa monetária induzidos pelas minas do Brasil seriam compensados por uma melhor permeabilidade do mercado, o que ele chama substituir as riquezas naturais pelas riquezas fictícias (57). O Brasil se acha assim participante do crescimento da economia mundial (58) e da constituição de novos pólos, até mesmo de novas nações, de que as colônias inglesas da América setentrional formam o arquétipo em vias de elaboração (59).

Isto na Histoire de deux Indes, vai resultar numa singular prosopopéia onde surpreende-se um orador-autor anônimo prestando uma vibrante homenagem à política ilustrada de Pombal a favor da naturalização dos índios do Brasil, política à qual um povo mal-educado não soube dar o seu justo valor: 
"Só em 1755, é que todos os brasileiros ficaram realmente livres (60). O governo os declarou cidadãos nessa época. Devem ter usufruído esse título da mesma maneira que os conquistadores. A mesma carreira foi aberta a seus talentos; e puderam aspirar às mesmas honrarias. Um acontecimento como este, tão próprio a enternecer corações sensíveis, mal foi notado.

(...) Criticam com amargura as operações erradas do governo: e quando lhe acontece, por acaso, fazer uma boa, calam-se. Digamme, povos, será essa a gratidão que deveis àqueles que cuidam de vossa felicidade?" (t. V, p. 107-108).

Esse elogio, pouco sutil, da política portuguesa publicado três anos depois da queda de Pombal teria sido bem-vindo em Lisboa alguns anos antes: em 1780 deve ter sido interpretado como falta de diplomacia. Raynal, é verdade, evoca um ministério exclusivo, que estabelecera um sistema de "privilégio exclusivo" (t. V, p. 115) e de "monopólio" (t. V, p. 119) - alusão à Companhia geral do Grão Pará e do Maranhão suprimida em 1778 mas o fracasso é imputado em grande parte à incapacidade das próprias populações indígenas em administrar uma liberdade outorgada sem a educação que a deveria ter acompanhado tanto quanto em desligar-se de uma economia primitiva baseada na caça e na colheita (61). Nem por isso o Brasil colonial deixa de ser uma cópia freqüentemente caricatural da metrópole: superstição, enclausuramento das mulheres, indolência, remetem a uma imagem da Europa do Sul, complacentemente veiculada pelos viajantes, a literatura ou a ópera. As Luzes divulgadas da Amazônia até o rio do Prata só fazem atenuar esse quadro lamentável de uma nação degenerada (62), depois dos Grandes Descobrimentos que haviam transformado um "povo ativo, generoso, inteligente" (t. I, p.4l) em vassalo da Espanha $\mathrm{e}$, posteriormente, da Inglaterra. Mas, ao contrário de sua vizinha oriental, Portugal tem condição de fugir da espiral da decadência e do "mais bárbaro despotismo"(t. V, p. 200).

Num curioso canto amebeu, onde se distinguem as vozes, vez ou outra discordes, de Raynal e Diderot, a Histoire des deux Indes propõe um projeto de reforma para "o Brasil, esta grande colônia que nunca foi o que devia ser” (t. V, p. 197). Nela podem ser identificados alguns dos princípios que orientam o pensamento político de Raynal na sua análise geral da expansão européia fora de seu continente de origem: recusa dos monopólios, liberdade de comércio, desenvolvimento agrícola, desconfiança absoluta em relação ao imperialismo comercial e financeiro da Grã-Bretanha - "todo o ouro do Brasil toma o caminho do rio Tâmisa"(t. V, p. 187) -, denúncia 
dos efeitos econômicos perversos da religião católica, elogio da revolução pedagógica lentamente elaborada na Europa e que se difunde nas colônias pela mediação das classes dominantes ilustradas (63). Tal revolução deveria ser favorecida por uma forte imigração proveniente das regiões nórdicas do velho continente e da América setentrional, a qual iria regenerar os "portugueses crioulos", ou seja, nascidos no Brasil, ao desenvolver uma economia agroexportadora "para as necessidades ou os deleites da Europa" (t. V, p.202, 200).

A Histoire des deux Indes convida, portanto, a uma recolonização do Brasil baseada em princípios que substituiriam o ferro dos conquistadores pelas leis progressistas da economia de mercado e do livre-cambismo de mercadorias e homens. Participantes desse sistema, os ameríndios não terão outra possibilidade senão fundir-se no grande movimento civilizador que doravante rege o mundo: este povo de ateus felizes retratado com tanta sensibilidade por Diderot é um sonho de filósofo, mais ameaçado ainda do que o dos taitianos do Supplément au voyage de Bongainville. Ao meio dos fantasmas numerados de Raynal que avalia as populações brasileiras com precisão aritmética (t. V, p. 201, 202), os homens da floresta e do rio (64) são os testemunhos de uma humanidade que as leis universais das Luzes condenam à integração ou à morte (65).

\section{Notas}

1 Philippe Bonnichon. Imagem e conhecimento do Brasil: difusão na França de Luís XII até Luis XIII, Naissance du Brésil moderne 1500-1808. Sob a direção de Katia de Queiros Mattoso, Idelette Muzart-Fonseca dos Santos e Denis Rolland. Paris, Presses de l'Université de Paris-Sorbonne, 1998, p. 11-31.

2 Andrea Daher. As singularidades da França equinocial. História da missão dos padres capuchinhos no Brasil (1612-1615). La France-Amérique (XVI'-XVIII ${ }^{e}$ siècle). F. Lestringant (ed.). Paris, Honoré Champion, 1998, p. 289-313 (com ilustrações); Denis Crouzet. A respeito de alguns olhares de viajantes franceses sobre o Brasil (cerca de 1610-cerca de 1720). Naissance du Brésil moderne 1500-1808, cit., p. 67-117.

3 Thierry Wanegffelen. Rio ou a verdadeira Reforma: a França antártica. Nicolas de Durand de Villegagnon entre Genebra e Roma. Naissance du Brésil moderne 1500-1808, cit., p. 159-175.

4 René Duguay-Trouin. Mémoires. Paris, 1974, p. 193. A edição original é de 1730. O texto vem acompanhado de um interessante mapa dobrável: Mapa da 
baía e cidade de Rio-Janeiro (fora do texto, p. 198-199 da edição de 1774), que dá uma imagem bastante exata de sua dimensão urbana no início do século XVIII.

5 Op. cit., p. 199-202.

6 Journal du voyage fait par ordre du Roi à l'Equateur. Paris, Imprimerie Royale, 1751 .

7 Relation abrégée d'un voyage fait dans l'intérieur de l'Amérique méridionale depuis la côte de la Mer du Sud jusqu'aux côtes du Brésil et de la Guyane en descendant la rivière des Amazones. Paris, Veuve Pissot, 1745, p. 47. Esse relato acadêmico sobre uma viagem iniciada no Peru em 1736, foi publicado novamente com numerosas variantes nas Mémoires de l'Académie des Sciences (1749); convém ler também Carta do Sr. de la Condamine, que contém observações sobre o rio das Amazonas (Journal encyclopédique, n. 1, p. 446-456, 1770); ver Gérard Blanc, No país das Amazonas: segunda viagem de La Condamine. F. Moureau (ed.), Le second voyage ou le déjà-pu, Paris, Klincksieck, 1996, p.2937.

8 Journal des observations physiques, mathématiques et botaniques faites par ordre du roi sur les côtes orientales de l'Amérique méridionale et dans les Indes occidentales depuis l'année 1707 jusques en 1712. Paris, Giffard et Mariette, 17141725, v. 3 , in $4^{\circ}, 50$ ilustrações de botânica.

9 Relato no Journal encyclopédique (1773, 8, p. 113-136): Carta para o senhor de la Condamine sobre sua viagem de volta pelo rio Amazonas.

10 E.-T. Hamy. Joseph Dombey, médecin, naturaliste, archéologue, explorateur du Pérou, du Chili et du Brésil; (1778-1785). Sa vie, son oeuvre, sa correspondance. Paris, 1905.

11 Ver o estudo de Jean Chaï, A respeito de Fusée-Aublet, boticário botânico em Caiena em 1762-1764. COMPTES RENDUS DU CONGRÈS NATIONAL DES SOCIÉTÉS SAVANTES, 90. Nice 1965. Section des Sciences, t. III: Histoire des Sciences, Paris. 1966, p. 59-62.

12 Histoire naturelle, civile et géographique de l'Orénoque. Avignon, 1758, 3 v.

13 Numa Broc La Géographie des philosophes. Géographes et voyageurs français au XVIII siècle. Paris, 1975; Yves Lassus. Les naturalistes français en Amérique du Sud. XVI $I^{e}$-XIX eiècles. Paris, CTHS. 1995.

14 Reeditados por Raymond Trousson, L'Arcadie. Genève, Slatkine, 1980. O texto parece ter sido redigido por volta de 1795 .

15 O ABC (1762). In: Raymond Naves (ed.), Dialogues et anecdotes philosophiques. Paris, Garnier, 1966, p. 297. 
16 Ver o excelente Dossiê Brasil dos viajantes. Revista USP, n. 30, 354 p., jun./ ago. 1996.

17 Reflexão de Cacambo dirigida aos Oreillons canibais (Candide, cap. XVI).

18 Dictionnaire philosophique. Ch. Mervaud (ed.), Oeuvres complètes, 35 v. Oxford, Voltaire Foundation, 1994, t. I, p. 390-391; Engana-se Voltaire ao citar Bayle, trata-se de Mathurin Veyssière de la Croze e de seus Entretiens. Amsterdam, 1733, p. 282.

19 Michèle Duchet. Diderot et l'Histoire des deux Indes ou l'écriture fragmentaire. Paris, 1978; Gianluigi Goggi, Algumas observações sobre a colaboração de Diderot na primeira edição da Histoire des deux Indes. In: Hans-Jürgen Lüsebrink \& Manfred Tietz (eds.), Lectures de Raynal. "L'Histoire des deux Indes” en Europe et en Amérique au XVIII siècle. Oxford, The Voltaire Foundation, 1991 (Svec 286), p.17-52.

20 Frank Lestringant. A experiência colonial da França no século XVI (Brasil e Flórida). In: Hans-Jürgen Lüsebrink \& Manfred Tietz (eds.), L'Histoire des deux Indes : fontes, reescrituras, representações. Oxford, Voltaire Foundation, 1995 (Svec 333), p.173-188.

21 Juízo expresso já em 1770 e freqüentemente reiterado pelo filósofo. Michèle Duchet, Anthropologie et histoire au siècle des Lumières. Paris, Maspéro, 1971, p. 470.

$22 \mathrm{O}$ autor da análise sucinta desse atlas, que o precede na edição de 1780, observa que Raynal recebera suas informações sobre as novas divisões do Brasil "de portugueses muito bem instruídos da extensão desses governos” (p.15).

23 Anthony Strugnell. Diderot pesquisador: novos dados sobre os livros emprestados por Diderot da Biblioteca do Rei entre 1775 e 1782. Recherches sur Diderot et sur l'Encyclopédie, n. 8, p. 12-19, 1990.

24 Guillaume-Thomas Raynal. Histoire philosophique et politique des établissements et du commerce des Européens dans les deux Indes. Genève, Jean-Léonard Pellet, $1780,10 \mathrm{v} ., \mathrm{em} 8^{\circ}$ e um atlas com 50 estampas no formato em $4^{\circ}$ : essa será nossa edição de referência. Existe outra em quatro volumes, em $4^{\circ} \mathrm{com}$ atlas do mesmo formato. Anatole Feugère, Bibliographie critique de l'abbé Raynal. Angoulême, 1922, n. 44-45. Ver G. Goggi, Os contratos para a terceira edição da Histoire des deux Indes, Dix-Hnitième Siècle, n. 16, 1984, p. 261-277.

25 Anthony Strugnell. Diálogo e discordância ideológica entre Raynal e Diderot: o caso dos ingleses na Índia. L'Histoire des deux Indes: réécriture et polygraphie, cit., p. 409-422.

26 Op. cit., p. 37.

27 Art. Brésil. Paris, Panckoucke, 1784, t. I., p. 396-413. 
28 "Não se conhece ódio nacional mais profundo e ativo do que o dos portugueses para com a Espanha. Tal aversão (...) não os impediu de emprestar a maior parte de suas máximas de um vizinho cujas forças temiam tanto quanto lhes abominavam os costumes" (Livro IX, t. V, p. 10).

29 Manfred Tietz. A Espanha e a Histoire des deux Indes do abade Raynal. In: Lectures de Raynal, cit., p. 99-130.

30 M. Duchet. Anthropologie et Histoire, cit., p.170-172.

31 A política da Companhia das Índias é demoradamente analisada no livro IV, 1780, t. II. Ver Philippe Haudrère. La Compagnie française des Indes au XVIII siècle. Paris, 1989.

32 M. Tietz. op. cit., p.101, n. 6.

33 Kenneth Maxwell. Pombal, Paradox of the Enlightenment. Cambridge, University Press. 1995.

34 Maria Adelaide S. Marques. A Real Mesa censória e a cultura nacional. Coimbra, 1963 (lista das obras proibidas de 1768 até 1814).

35 Manfred Tietz. A visão correlativa da Espanha e de Portugal nas três versões da Histoire des deux Indes (1770, 1774, 1780). In: L'Histoire des deux Indes: réécriture et polygraphie, cit., p. 263-277.

36 Continua: "provavelmente porque, numa página de seu livro, esse se permitiu brincar dizendo que em nossas igrejas folgamos com queimar velas em plena luz do dia. É preciso admitir que falar assim deve ser crime capital em Portugal, onde se queimam mil vezes mais velas do que na França; digo que essa é provavelmente a razão que o fez proibir por não acreditar que os portugueses estejam em condição de entender o resto da obra." Mon demi-tour de France par la Flandre autrichienne, l'Angleterre, le Portugal et l'Espagne. Ms aut., p. 45-46. Col. do autor. Esse viajante ilustrado era de Douai (Norte da França) e talvez descendente de um inglês jacobita.

37 Roberto Ventura. Leituras de Raynal na América Latina nos séculos XVIII e XIX. In: Lectures de Raynal, cit., p. 341-359.

38 Presença francesa no movimento democrático baiano de 1798. Bahia, 1969.

39 Autos de devassa da inconfidência mineira. Rio de Janeiro, 1936, II, p. 95.

40 Tradução do português: Ibid., t. IV, p. 180.

41 Id., Ibid, t. IV, p. 207.

42 Livro XI, cap. XXIV, 1870, t. VI: Notar-se-á porém, a aplicação singular da teoria dos climas às relações entre senhores e escravos: o temperamento ardente das africanas traz esta reflexão do filósofo, amigo da liberdade, que evoca 
“certa atração picante de beleza que se descobre nas negras tão logo o hábito familiarizou o olhar com a cor delas" (p. 185)!

43 Livro I, cap. XVIII: "A instituição da cavalaria, uma daquelas que mais elevaram a natureza humana: $\mathrm{o}$ amor à glória substituindo $\mathrm{o}$ amor à pátria; $\mathrm{o}$ espírito depurado da escória dos séculos bárbaros, nascido dos próprios vícios do governo feudal para the reparar ou temperar os males: reapareceu então a cavalaria nas margens do rio Tejo, com todo o brilho que tivera ao nascer na França e na Inglaterra" (t. I, p. 188).

44 A. Devyer. Le sang épuré. Les préjugés de race chez les gentilshommes français de l'Ancien Régime (1560-1720). Bruxelles, 1973.

45 Livro I, cap. XXVIII, t. I, p. 288.

46 A "análise sucinta deste atlas" (p. 15), identifica-lhe outra fonte "o belo mapa espanhol do Senhor La Crux (La Cruz) (...) que nem público é”.

47 Gravura de J.-B. Dambrun datada de 1780 (Carta: "Eis o tributo que paga o Rei de Portugal" e referência ao livro I, t. I, p. 165: declaração ameaçadora do duque de Albuquerque, vice-rei das Índias, ao rei da Pérsia, mostrando-lhe "balas, granadas e sabres").

48 Ver Frank Lestringant. Le cannibale. Grandeur et décadence. Paris, Perrin, 1994, chap. 11: O canibal das luzes: de Bougainville até Voltaire, p. 236-249. Diderot atribui uma origem insular ao canibalismo, tanto no Supplément a respeito da ilha dos Lanceiros quanto na Histoire des deux Indes (Livro III, chap. I, t. II, p. 3) ... no que concerne à Inglaterra dos tempos pré-históricos.

49 Voltaire. Dictionnaire philosophique, art. Antropófagos: "quer em batalha campal, quer em combates dispersos, matamos nossos vizinhos, pela mais vil recompensa contribuímos à alimentação dos corvos e vermes. Aí está o horror, aí está o crime; quando alguém é morto pouco importa para ele que seja comido por um soldado, um corvo ou um cachorro?" In: Christiane Mervaud, (ed.) Ouvres complètes. Oxford, Voltaire Foundation, 1994, t. 35-I, p. 346.

50 Appareil: "Aquilo que se prepara para fazer uma coisa mais ou menos solene" (Furetière).

51 Recherches philosophiques sur les Américains ou Mémoires intéressants pour servir à l'histoire de l'espèce humaine. Berlim, Decker, 1768, 2 v., ed. aumentada: Clèves, Baertstecher, 1772, $3 \mathrm{v}$.

52 Aliás, Raynal assinala nas milícias brasileiras uma repartição das raças que sugere um singular apartheid: "Os negros e os mulatos têm bandeiras próprias e os índios combatem com os brancos" (t. V, p. 101). Sobre as milícias formadas por Pombal, ver Maxwell, cit., p. 119-120 (com ilustrações dos dois tipos de regimentos). 
53 "A escumalha e a escória das sociedades policiadas podem às vezes formar uma sociedade bem ordenada" (t. V, p. 139).

54 Trata-se, em linhas gerais, da política de Pombal. Kenneth Maxwell. Pombal and the nationalization of the Luso-Brazilian economy. Hispanic American Historical Review, n. 47, p. 608-631, 1968.

55 Manuel Nunes Dias. A Companhia geral do Grão Pará e Maranhão 1755-1778. Pará, 1970, 2 v. José Ribeiro Junior. Colonização e monopólio no Nordeste brasileiro: a Companhia Geral de Pernambuco e Paraíba 1759-1780. São Paulo, 1976.

56 A respeito do antigo sistema colonial português, Raynal salienta as "vantagens inestimáveis da concorrência" (t. V, p. 95).

57 Jacques Accarias de Sérionne Les Intérêts des Nations de l'Europe développés relativement au commerce. Leipzig (na realidade: Leyde), Herdeiros de Weidmann e Reich, 1766, t. I, p. 25. Nesta obra, que ele dedicou a Catarina II, e na qual expressa uma sensibilidade muito nova aos fenômenos monetários, o cap. II é consagrado ao comércio português.

58 Anexados ao atlas, Raynal publica vários quadros, entre os quais o da "espécie, quantidade e valor dos objetos que o Brasil envia anualmente a Portugal, calculado segundo uma base comum, desde 1770 até 1775".

59 Sobre a realidade da colonização portuguesa no Brasil, convém ler a obra de Dauril Alden. Royal government in colonial Brazil. Berkeley/Los Angeles, University of California Press, 1968; e Francisco José Calazans Falcon. A época pombalina: política econômica e monarquia ilustrada. São Paulo, 1982.

60 Pelo decreto de 6 e 7 de junho de 1755, que concedia aos índios a completa liberdade e integração ... no âmbito da Companbia Geral do Grão Pará e Maranhão que viera substituir as reduções jesuíticas. Tal iniciativa política devia-se ao irmão de Pombal, Francisco Xavier de Mendonça Furtado, governador e capitão-geral das províncias amazônicas.

61 Os reformadores "tinham a certeza de que os índios iriam se apegar à lavoura e multiplicar-lhe as produções (...) e de que o espetáculo da própria felicidade afastaria os selvagens de suas florestas" (t. V, p. 109-110).

62 "As luzes, cujo abuso corrompe às vezes povos virtuosos, podem, se não apurar e reformar uma nação degenerada, pelo menos tornar mais raro o crime, lançar um verniz de elegância sobre a corrupção, introduzir nela uma hipócrita urbanidade e o desprezo pelo vício grosseiro" (t. V. p. 127-128).

63 "A luz parece reservada para as próximas gerações. Pode-se apressar essa revolução decidindo os grandes proprietários a fazer com que seus filhos sejam criados na Europa, reformando e aperfeiçoando a instituição pública em Portugal” (t. V, p. 206-207). 
64 Avalia-se em duzentos mil o número de selvagens ainda errantes pelo Brasil (t. V, p. 202).

65 Os contemporâneos foram sensíveis às contradições evidentes da Histoire des deux Indes. Seu tradutor húngaro, o jacobino Pál Oz, distingue nitidamente aquilo que, a respeito dos "brasileiros" vem de Diderot ou de Raynal. Olga Penke. A Histoire des deus Indes na Hungria no século das Luzes. Lectures de Raynal, cit., p. 277-278.

François Moureau é professor da Universidade de Paris-Sorbonne, Paris IV.

Tradução de Jean Briant. O original em francês - Le Brésil des Lumières françaises encontra-se à disposição do leitor no IEA-USP para eventual consulta. 